\title{
Em Tese
}

\section{LAS CIENCIAS SOCIALES EN ARGENTINA, SOCIOLOGÍA DE LA VIDA INTELECTUAL Y MERCADO EDITORIAL: ENTREVISTA CON EZEQUIEL GRISENDI} The Social Sciences in Argentina, Sociology of intellectual life and the editorial market: interview with Ezequiel Grisendi

\section{Entrevistado}

Rodolfo Ezequiel Grisendi

Professor do Departamento de Antropologia

Universidad Nacional de Córdoba (UNC), Argentina

egrisendi@gmail.com

(1) https://orcid.org/0000-0002-3999-2727 
Ezequiel Grisendi nació en 1980, en la Ciudad de Córdoba, provincia de Córdoba, Argentina. Es graduado en historia y doctorando en Ciencias Antropológicas por la Universidad Nacional de Córdoba (UNC). Actualmente es profesor regular y coordinador del área Teórico-metodológica del Departamento de Antropología de la Facultad de Filosofía y Humanidades, de la Universidad de Córdoba. También es investigador del Programa de Historia y Antropología de la Cultura (PHAC), con sede en el Instituto de Antropología de Córdoba (IDACOR), CONICET. Sus áreas de investigación se concentran especialmente en la Historia de las Ciencias Sociales y la sociología de la vida intelectual y editorial en Argentina y América Latina. En 2017, co-coordinó el panel sobre la sociología de las ediciones de libros en el XXXI Congreso ALAS, ocurrido en Montevideo/Uruguay. Participa, junto a otros investigadores de la Facultad de Ciencias Sociales (UNC), el proyecto "Hacer Sociología en Córdoba, entre las clases y las calles", que pretende documentar y recuperar la memoria de la licenciatura (graduación) en Sociología en la Facultad de Ciencias Sociales de la Universidad Nacional de Córdoba. Bajo la coordinación regional de Gustavo Sorá, integró el equipo argentino del proyecto INTERCo-SSH (International Cooperation in Social Sciences and Humanities).

\section{ENTREVISTA}

\section{¿Profesor Ezequiel Grisendi, podría contar sobre su trayectoria académico, en especial sobre su aproximación con la temática de la historia de las ciencias sociales y de las ediciones de libros?}

Mi formación como estudiante universitário fue en historia. Realicé mis estúdios de grado pensando em uma tesis sobre temas de historia de la antigüedad clássica griega pero finalmente reorienté mis interesses a los problemas de historia argentina. Este trânsito fue múltiple ya que me acercó a nuevas temáticas pero, fundamentalmente, a nuevos horizontes conceptuales y metodológicos; em primer lugar, porque me permitió uma aproximación al equipo de investigación que coordinaban Ana Clarisa Agüero y Diego García, ambos historiadores cordobeses, sobre historia cultural. Los énfasis de la perspectiva que distinguia este grupo eran tanto su atención a los fenómenos culturales inscriptos em coordenadas territoriales siempre em tensión y a la materialidade propia de cada modo expressivo, sean producciones artísticas, filosóficas o literárias. Em esse sentido, el presupuesto compartido, em primer término, era el de problematizar 
históricamente los pares conceptuales de centro y periferia o de tradición y modernidade, por mencionar apenas aquellas categorias que dominaban em las interpretaciones sobre Córdoba, su historia em particular, y su lugar em la historiografia, em general. Em segundo lugar, resultó muy esclarecedor el particular interés em reponer la pregunta por los soportes a través de los cuales viajan las ideas, las imágenes o los textos. Gustavo Sorá, antropólogo formado em el PPGAS del Museu Nacional-UFRJ, fungió como um verdadeiro promotor de interrogaciones acerca del mundo editorial. Em buena medida, el alcance de sus pesquisas interpeló a quienes frecuentamos los temas de historia intelectual o cultural para llevar a serio la dimensión material de la circulación de las ideas. El equipo se llamaba CEMICI (Cultura Escrita, Campo Intelectual, Mundo Impreso), fue dirigió Sorá durante muchos años, donde inscribí mis años de formación, llevó esa marca como distintivo: atender a las geografias inestables de la producción intelectual y interrogarse por la historia de los médios materiales de transmisión de la cultura. De este modo, mis opciones de investigación se han inscripto em espacios de discusión y producción conjunta generados em el equipo pero también em âmbitos de formación y debate que compartimos com otros colectivos como el Taller de Historia Intelectual, el Coloquio de Estudios sobre el Libro y la Edición o los diversos grupos de trabajos sobre historia de la sociologia em diversas jornadas.

Mi proximidade com la historia de las ciências proviene efetivamente del diálogo com Gustavo Sorá y sus investigaciones em esse mismo campo, y com mi intercambio com Alejandro Blanco, mi orientador de tesis e investigador del Centro de Historia Intelectual de la Universidad Nacional de Quilmes, quien conocía muy bien el tema luego de sus trabajos sobre la historia de la sociologia em Argentina y América Latina. Em ambos casos, la tarea de pesquisar el processo de desarrollo de las ciências sociales en general, y de la sociologia em particular, resultaba diretamente vinculada a la pregunta por los contextos de producción intelectual, a la reconstrucción de las trayectorias de formación de las principales figuras intervenientes y a recuperar la dimensión editorial em esa historia.

\section{En su tesis de doctorado y en artículos, usted enfocó la historia de la sociología en} Córdoba. ¿En qué medida esta historia desde Córdoba se distinguió del desarrollo de la sociología en otras provincias como Buenos Aires?

La preocupación por trazar uma historia de la sociologia em Córdoba fue, inicialmente, la de oferecer menos um relato localista de um processo excepcional y más la de reconstruir 
el recorrido histórico de um saber que, dados sus avatares a lo largo de um período de tempo relativamente extenso (desde 1890 hasta 1970, aproximadamente), me permitia considerar a la vez su problemática inserción em um médio intelectual territorialmente discreto pero cuyas referencias proyectaban uma geografia más vasta. Así, explorar la sociologia em Córdoba no me resultaba um tema interessante por su mera singularidade sino porque me permitia reponer variadas dimensiones de la historia social, política y cultural de Córdoba, de sus relaciones com otras ciudades y otras regiones. El punto de partido de esse trabajo era la incomodidade com ciertas formas de historizar las ciências sociales, em especial, aquellos relatos disciplinares fuertemente autocentrados em uma recapitulación escassamente problematizada donde la configuración presente parecia proyectarse anticipatoriamente hacia el passado; em muchas de essas teleologias, las justificaciones de los objetos de estúdio y la amplitudes de las preguntas eran escasas.

Por ello, mi interés por la historia de la sociologia em Córdoba no se fundó em vindicar um desiquilíbrio sino em oferecer uma mirada amplia de desarrollo de uma ciência social por fuera del caso más conocido (Buenos Aires), no apenas como uma versión "menor" o "desviada" sino como fenómeno com uma configuración propia, tensionado por su particular acumulación de experiências passadas, la morfologia social de la ciudad y de su universidad y de los contatos com otros espacios de saber. Explicitado mi punto de partida, mi trabajo buscó problematizar el supuesto tradicionalismo conservador que se adjudicaba a Córdoba, su escenario cultural y universitário, para mostrar la dinâmica de sus variados emprendimientos intelectuales, políticos y editoriales habían permitido la creación de uma cátedra universitária de sociologia, la dedicación com certa regularidade de um conjunto de agentes sociales a las discusiones teóricas sobre la sociologia, la promoción de lecturas, la realización de conferencias o la edición de ciertos textos que, lejos de reforzar esa conjecturada "quietude provinciana", delineaban outro escenario de intenso intercambio tanto com Buenos Aires como otras capitales culturales americana y europeas. La opción de uma periodización de larga duración para observar la sociologia em Córdoba responde, basicamente, a dar cuenta de diferentes momentos em su desarrollo particular y em sus vínculos com otras latitudes. Em efecto, la consolidación de la carrera de sociologia de la Universidad de Buenos Aires a fines de los años cincuenta y su proyecto de modernización de las ciências sociales em Argentina tuvo sus efectos em Córdoba donde, además de la creación de um instituto de sociologia y uma publicación, no se organizo um espacio docente ni de investigación equivalente em dinamismo al conducido por Germani. La subordinación institucional e intelectual de la sociologia a las 
ciências jurídicas, que se reforzaba em uma diferencia de las procedência sociales de los practicantes de la disciplina, modelo outro patrón de desarrollo académico no exento de impugnaciones y desafios.

En Brasil la llamada "sociología de cátedras" tuvo mayor impulso a partir de los años 20, a través de las sillas de las escuelas normales. ¿Es posible decir que la "sociología de cátedras" tiene un papel más central en la institucionalización de la sociología en Argentina, impulsada principalmente a partir de las facultades de Derecho?

Em efecto, el processo inicial de expansión de la disciplina em Argentina estuvo ligada a las diversas cátedras de sociologia creadas, primero em Buenos Aires (em la Facultad de Filosofía y Letras), y luego em el resto de las universidades nacionales a comienzos del siglo XX. Salvo algunas expceciones, frecunetemente inscriptas em carreras orientadas a la formación professional de abogados o de carreras humanísticas, las cátedras de sociologia combinaban um grupo de lecturas generales sobre los fundamentos epistemológicos de la disciplina, um recorrido histórico de sus antecedentes (filosóficos y literários) y um repasso enciclopédicos por las variadas posiciones teóricas. La creación del Instituto de Sociología em la Universidad de Buenos Aires em la década de los cuarenta, sirve de primer hito em la organización de la disciplina y em ampliar sus horizontes fuera de las cátedras. Sin dudas, el segundo gran hito, la creación de la carrera de grado em la misma universidad. Estos ciclos fueron acompanhados por el desarrollo de otras experiências de institucionalización como las de La Plata, Santa Fé o Córdoba que resulta importantes tanto por su contraste com la experiência porteña como por los vínculos entre ellas.

El desarrollo de la sociología brasileña, aún en las primeras décadas del siglo XX, fue marcado por la intensa publicación de libros y manuales didácticos de sociología, contribuyendo a la difusión de las ideas sociológicas en el país mismo antes de haber cursos superiores en el área. ¿Cómo percibes, en el contexto argentino, las publicaciones de libros y manuales de sociología, como los de autoría de intelectuales importantes como Enrique Martínez Paz, Raúl Orgaz y Alfredo Poviña?

La divulgación de la sociologia em Argentina em las primeras décadas del siglo XX estuvo fuertemente vinculada tanto a los trabajos publicados em revistas como em los libros de sínteses. La misma noción del género editorial "manual" supone enfrentarse a 
especificidades particulares que, em muchos casos, sólo emergen a partir de algunos procedimentos metodológicos como la comparación. Así, poner em relación histórica y/o contemporânea diferentes "manuales" de sociologia iluminan ciertas persistências genéricas pero también algunas diferencias respecto de sus produtores. Em buena medida, los trabajos de Francisco Ramos Mejía, Juan Agustín García (h), Leopoldo Maupas o Ernesto Quesada, publicados entre 1880 y los años del Centenario de la Revolución de Mayo (1910), sirvieron tanto de material de consulta para los estudiantes de las cátedras universitárias de sociologia aunque también como dispositivo de intervención em la arena intelectual nacional y extranjera. Em ambos sentidos, el formato de "manual" o libro de sínteses, permitió a muchas de estas figuras disputar sentidos respecto de los alcances de uma disciplina com fronteras aún indefinidas y erigirse como los más capacitados intérpretes de um saber em franca expansión, um tipo particular de herramienta hermenêutica, em parte reflexión filosófica y em parte dispuesta a um análisis de la tensión entre el passado y el presente de la sociedade.

El caso de Juan Agustín García (h) resulta especialmente interessante em tanto que su libro "Introducción al estúdio de las ciências sociales argentinas" se planteó como sínteses, como um estado de la cuestión pero también assoma em él certo tono programático respecto del rumbo futuro que debe tomar la sociologia. Por ello, además de resumir líneas teóricas o problemas epistemológicos, muchos de éstos "manuales" proyectaban modos de practicar la sociologia y su interpretación debe inscribirse em la trayectoria particular de cada agente, em el estado del campo universitario y em las coordenadas del mercado editorial nacional o regional. Por caso, el libro "Estudios de Sociología" de Raúl Orgaz es menos uma sínteses dispuesto para reproducir esquemas teóricos que uma compilación de trabajos aparecidos em diversas revistas que servían de actualización para lectores iniciados. Esse formato de libros fue el que privilegió Orgaz hasta comienzos de los años treinta, donde comienza a inclinarse por el formato de "tratado" o "manual" em la medida em que su posición académica y su prestigio se consolidaron. Por oposición, las obras de sínteses son omnipresentes em el recorrido intelectual de Alfredo Poviña, contribuyendo com libros com el formato de "manual" aún sin poseer uma situación universitária privilegiada. Acaso su "Historia de la sociologia latino-americana" de 1941, editado em México por Fondo de Cultura Económica com prólogo de José Medina Echavarría sirva de indicador sobre el perfil de professor y divulgador antes que de investigador que caracterizó a Poviña a lo largo de su carrera 
académica. Sus sucessivos libros de sínteses publicados desde esos años parecen reforzar esa predilección.

Siguiendo en esa pista, preponderaba alguna corriente teórica y objetivos en la defensa de la enseñanza de sociología, marcadamente por estos intelectuales?

Entiendo que antes que uma línea de enseñanza definida, los manuales o libros de sínteses fungieron como marco amplio de patrones imaginados de la sociologia, tensionada como saber subordinado a diversas formaciones profesionales (especialmente vinculada al derecho) pero también como ámbito privilegiado de innovación intelectual. Em el caso de las Facultades de Derecho, la asignatura ocupó, em general, um lugar de formación complementaria a las matérias estrictamente jurídicas em la formación de grado; em algunos casos, inclusive, fue desplazada de la formación inicial y dispuesta em la formación de postgraduación para quienes aspiraban al título de doctorado. Esa relativa situación periférica, fuente de tensión entre quienes le imputaban meros fines especulativos y quienes sostenían a la sociologia como saber directriz dentro de las ciências sociales y humanas, permitió igualmente recorridos teóricos variados desde um ciclo dominado por el cientificismo de corte sociológico o biologicista em el giro de siglo XIX a XX hasta las reacciones vitalistas y espiritualistas de los años veinte, passando por las ambíguas lecturas del proyecto Durkheimiano o de los libros de Max Weber y Georg Simmel.

A pesar de las carreras de sociología y antropología, especialmente, si institucionalizar en la Argentina más recientemente (si se compara a Brasil), las ciencias sociales, en general, siempre desempeñaron un papel relevante en el debate público. En este sentido, ¿cuál es el lugar de las ciencias sociales en la sociedad argentina?

Si bien la institucionalización de las ciências sociales em Argentina resulta tardía respecto de otros casos nacionales em relación a la creación de carreras de graduación y postgraduación, su presencia universitária y su vida pública parecen menos desfasadas. No sólo por la temprana creación de cátedras de sociologia y antropologia em diferentes unidades académicas desde comienzos del siglo $X X$, sino porque entre quienes se inscribieron em la tradición de las ciências sociales argentinas, la política no fue um ámbito completamente extraño. Fuera a partir de su desempeño como funcionário judicial, como militante partidário, agente diplomático o burocrata de la administración estatal pero 
también como scholar o pensador diletante, el horizonte de la discusión pública no es ajena a los y las cientistas sociales argentinas; em parte debido a la estrutura social y los modos de integración a la vida política nacional, y em parte dado el perfil particular de la universidad em Argentina, resulta difícil pensar em uma escisión entre los mundos del saber sobre la sociedade y la política. Lejos de constituir uma continuidade inmanente, la variabilidade histórica de la politización de la vida universitária argentina permite apreciar ciclos de mayor o menor incidência de las ciências sociales em el debate público. Foco privilegiado por la represión estatal ilegal durante las dictaduras militares, los âmbitos universitários de las ciências sociales han resultado espacios singularmente dinâmicos para la articulación de proyectos críticos contra el establishment político y económico, visibilizando demandas sociales y prácticas de producción de conocimiento avaladas por tradiciones de investigación prestigiosas. Em tanto campo de fuerzas, el espacio de las ciências sociales em Argentina no es homogéneo pero resulta significativo remarcar certa "vocación profesionalizada" de interpelación del debate público del saber sobre lo social.

\section{En sus trabajos usted también atenta para cambios en el proceso de} institucionalización de las ciencias sociales en América Latina, después de los años 50. ¿Podría hablar un poco de este proceso de internacionalización y circulación de las ideas?

La institucionalización de las de las ciências sociales em el marco latino-americano es uma temática que há ganado interés entre los investigadores de la región em tanto objeto de estúdio sistemático, más allá de los relatos producidos por las propias instituciones. Aquí, entendo, que el desplazamiento desde las narrativas nacio-centradas a uma perspectiva de escala transnacional há operado como punto de partida central para la investigación de processos complejos de circulación de ideas. Como lo han mostrado Alejandro Blanco o Fernanda Beigel, para los casos de la Asociación Latino Americana de Sociología (ALAS) o de la Facultad Latino Americana de Ciencias Sociales (FLACSO), el fenómeno de consolidación de las ciências sociales se inscribe em coordendas territoriales más amplias que los espacios nacionales. Este cambio de perspectiva, no supuso necessariamente desestimar las especificidades de los ritmos locales, pero si beneficiar uma mirada más integral que complejice las historias disciplinares em comunicación com otras zonas de la producción cultural. Este marco de referencias tanto conceptuales como metodológicas han orientado algunas de mis aproximaciones. 
Si esse cambio de escala territorial há compuesto nuevas cartografías em la aproximación al estúdio de las ciências sociales em la región, la atención a la circulación de personas y objetos materiales sobre los cuales circulan las ideas son dos dimensiones de análisis complementarias. Estos énfasis hán permitido, em primer lugar, um empleo cualificado de la noción de "red" para estabelecer los contatos efectivos entre agentes ubicados em diversas posiciones del campo de producción de ciências sociales, reconstruir trayectorias individuales y colectivas de grupos de pesquisa, diagramar los alcances de proyectos transnacionales de investigación aplicada o ponderar "afinidades electivas" entre quienes alentaron empresas de enseñanza y divulgación del conocimiento social. Em segundo lugar, y relacionado com la pregunta siguiente, el llamado "giro material", esto es el estúdio de las condiciones de selección y distribución de los bienes simbólicos em soportes impresos, sean éstos revistas u obras publicadas em formato libro, há advertido sobre las capacidades y limitaciones concretas em la transmisión de modelos teóricos, em la difusión de pesquisas de campo o em la comunicación de informes técnicos que suponen los modos de inscripción em dispositivos editoriales, sean o no impresos.

\section{Me gustaría que hable sobre sus investigaciones dirigidas a las ediciones de libros.}

\section{¿A partir de qué aportes teóricos y metodológicos usted ha pensado estas cuestiones?}

Mi acercamiento al trabajo sobre el mundo de la edición de libros es, em buena medida, uma "marca" del equipo de investigación que integro em Córdoba, y resultado de um esfuerzo sistemático de Gustavo Sorá por reflexionar profundamente sobre esse universo de investigación. Los puntos de partida para dichas reflexiones han provenido de la historia del libro y la lectura (mediante Robert Darnton, Jean-Yves Mollier o Roger Chartier), la antropologia de la cultura escrita (em especial, Jack Goody) y la sociologia de la edición (com referencias que incluyen a Pierre Bourdieu, Gisèle Sapiro o John B. Thompson). Em la medida que los diversos objetos de estúdio fueron reclamando instrumentos de indagación y perspectivas analíticas pertinentes, cada uma de estas referencias me han servido como insumo ativo antes que como grilla fija. Así, el estúdio de um emprendimiento editorial, sea uma revista, uma colección de libros o um libro em particular, condensan pliegues de um espacio social com posiciones y funciones particulares, que permiten imaginar circuitos de comunicación entre agentes com intensidades y direcciones historicamente variadas (editores, impressores, autores, distribuidores, representantes, gerentes comerciales, libreros, lectores), articulados em 
fases de producción, circulación y consumo de um bien impresso, regulados por um mercado más o menos autónomo. Esa "vida editorial" de las ideas lo que me há llamado la atención como práctica multidimensional para pensar el desarrollo de las ciências sociales em América Latina, em general, y em Argentina, em particular.

\section{En una coyuntura de amplia difusión de internet y de divulgación del conocimiento académico por medio de revistas electrónicas, ¿podríamos considerar el libro físico un aún destacado objeto para pensar la circulación internacional de bienes simbólicos?}

Aunque resulta um tema que demandaria uma ampliación de mis argumentos com mayor precisión y extensión que lo que aqui puedo aprovechar, pienso que la expansión de los médios electrónicos para la divulgación del conocimiento académico há resignificado los alcances del publico, potencialmente interessado em la lectura de los resultados de investigaciones producidas em el ámbito universitário. Es indudable que las possibilidades de trabajo colaborativo y de intercambio de información entre colegas há sido fortalecido por internet. Sin embargo este vertiginoso ritmo de flujo de información no parece haber opacado totalmente al libro como vía de transmisión del conocimiento académico. Em primer lugar, porque ante las profesías de "desaparición del libro em papel" la indústria editorial registra el avance de la venta de e-books pero no um derrumbe absoluto de las ventas de libros físicos; em segundo lugar, el libro como unidad simbólica continua funcionando como referencia de obra em tanto que aglutina esfuerzos cognitivos y sociales bajo um descriptor temático em torno a la figura de um autor o um conjunto de autores. Em tercer lugar, como lo há demostrado Alejandro Dujovne, especialmente em las ciências sociales y humanas, el prestigio associado a la edición de um libro como resultado de um proyecto de investigación, continua operando como indicador de "valor" em el campo de producción restringida (público académico) pero también como visibilizador de esa empresa intelectual em um universo de lectores massivo. Pensar la internacionalización de la circulación de los bienes simbólicos supone atender a las especifidades de los soportes que la contienen, los públicos que éstos habilitan y las estratégias de traducción linguística que cada mercado editorial les impone.

Por último, ¿podría hablar un poco sobre la experiencia del proyecto "Hacer Sociología en Córdoba. Entre las aulas y las calles"? 
El proyecto "Hacer sociologia em Córdoba" há sido resultado de um notable esfuerzo colectivo de investigadoras/es, bajo la coordinación de Soledad Segura y em el marco de la carrera de Sociología de la Facultad de Ciencias Sociales de la Universidad Nacional de Córdoba, por reconstruir los avatares de la disciplina sociológica em sus diversas inscripciones institucionales, políticas e intelectuales. La pluralidade de miradas sobre esse recorrido fue abordado a través de la recolección de testimonios de primera mano, entrevistas em profundidad com protagonistas de la sociologia em Córdoba, la revisión de documentación original, publicaciones periódicas y obras significativas de esse passado, pero también recuperando las voces de quienes, em la actualidad, se desempeñan al frente de cátedras de sociologia. El proyecto ilumina, pienso, uma trayectoria compleja apelando a la consideración de los debates disciplianres y coyunturas políticas que atravesaron a la sociologia. El resultado del proyecto es um documental audiovisual accesible em internet para beneficiar su divulgación. ${ }^{1}$

\section{Agradezco la entrevista concedida}

\section{PUBLICACIONES DEL AUTOR}

GRISENDI, E. El Centro de la periferia: internacionalización de las ciencias sociales y redes académicas latinoamericanas. Manuel Diegues Junior y los avatares de la sociología del desarrollo. Crítica e Sociedade: revista de cultura política. v. 4, n. 2 Dossiê: pensamento social, desenvolvimento e desafios contemporâneos dez. 2014.

GRISENDI, E. ¿Cómo interpretar el Cordobazo? Dos Lecturas Sociológicas. Intersticios. UNC, V. 2, n. 3, 2013

GRISENDI, E. Los "escritores de provincia" como tema: Mediadores culturales y circuitos literarios "periféricos" (Córdoba, 1940-1960). Trabajo y Sociedad, № 22, Santiago del Estero, Argentina, Verano 2014.

GRISENDI, E . "Los poetas del interior en el mapa lírico de la nación" Alberto Díaz Bagú entre poesía y edición (Córdoba, 1944-1959). Prismas - Revista de Historia Intelectual, n. 17, 2013.

GRISENDI, E. Enrique Martínez Paz. La sociología entre la institución universitaria y las tradiciones intelectuales (1908-1918). In: A.C. Agüero y D. García (Eds.), 72 Culturas

\footnotetext{
${ }^{1}$ Las entrevistas del proyecto "Hacer Sociología en Córdoba" están disponibles en el canal de la Facultad de Ciencias Sociales - UNC, en el link: https:/www.youtube.com/channel/UCGGOC-D2OI7W0ZwQ2Oe43A.
} 
Interiores. Córdoba en la geografía nacional e internacional de la cultura. La Plata: Al Margen, 2010.

GRISENDI, E. ; REQUENA, P. La Universidad Nacional de Córdoba entre 1918 y 1946. In: Gordillo, M. y Valdemarca, L. (coord.). Facultades de la UNC. 1854-2011. Saberes, procesos políticos e institucionales (pp. 93-104). Córdoba: Editorial de la Universidad Nacional de Córdoba,2013

GRISENDI, E. Internacionalización de las ciencias sociales y redes académicas latinoamericanas. Crítica e Sociedade: revista de Cultura Política. V. 4, n. 2, 2014.

\section{NOTAS}

\section{TíTULO DA OBRA}

As ciências sociais na Argentina, trajetórias e edições de livros: entrevista com Ezequiel Grisendi.

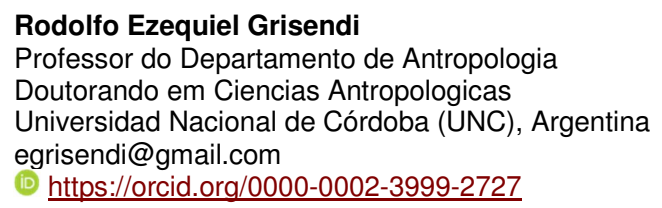

\section{Ana Martina Baron Engerroff}

Programa de Pós-Graduação em Sociologia Política

Universidade Federal de Santa Catarina, Brasil

anambaron@hotmail.com

(1) https://orcid.org/0000-0002-3957-0428

\section{FINANCIAMENTO}

O presente trabalho foi realizado com apoio da Coordenação de Aperfeiçoamento de Pessoal de Nível Superior - Brasil (CAPES) - Código de Financiamento 001.

\section{CONFLITO DE INTERESSES}

Não se aplica.

\section{LICENÇA DE USO}

Os autores cedem à Em Tese os direitos exclusivos de primeira publicação, com o trabalho simultaneamente licenciado sob a Licença Creative Commons Attribution 4.0 Internacional (CC BY). Estra licença permite que terceiros remixem, adaptem e criem a partir do trabalho publicado, atribuindo o devido crédito de autoria e publicação inicial neste periódico. Os autores têm autorização para assumir contratos adicionais separadamente, para distribuição não exclusiva da versão do trabalho publicada neste periódico (ex.: publicar em repositório institucional, em site pessoal, publicar uma tradução, ou como capítulo de livro), com reconhecimento de autoria e publicação inicial neste periódico.

\section{PUBLISHER}

Universidade Federal de Santa Catarina. Programa de Pós-Graduação em Sociologia Política. Publicado no Portal de Periódicos UFSC. As ideias expressadas neste artigo são de responsabilidade de seus autores, não representando, necessariamente, a opinião dos editores ou da universidade.

\section{HISTÓRICO}

Recebido em: 22 de maio de 2019 Aprovado em: 22 de maio de 2019 